\title{
DC Brushed Electrical Motor Performance Analysis Study of a Proton Exchange Membrane Fuel Cell (PEMFC) Automotive Propulsion System
}

\author{
F. Othman, M. H. A. M. Fakharuzi, S. Hanapi, N. Jenal, and K. I. Sainan
}

\begin{abstract}
The study is conducted to analyse the efficiency of DC electrical power curve by simulating the different optimum performance of DC electrical motor. The study is accomplished by performing series experiments on DC motor with various current loads and gear ratios and also by constructing the mathematical modelling for the propulsion system data mapping. The outcome of the study shows that DC brushed motor give convincing result on the performance based on power consumption and the completion time. The DC brushed motor was selected based on the results which produce the best configuration for the urban car PEMFC electrical propulsion system.
\end{abstract}

Index Terms - DC brushed motor performances, electrical vehicle, Protons Exchange Membrane Fuel Cell (PEMFC), shell eco-marathon Asia.

\section{INTRODUCTION}

Electric vehicle $(\mathrm{EV})$ is a road vehicle which utilizes electric propulsion system. EV is the perfect solution for the environmental problem that was caused by the hazardous carbon emission of the conventional transportations. The environmental problem became much worst with the increasing number of vehicle used due to the increased of human population [1], [2]. By neglecting the cost, the zero emission hydrogen fuel cell EVs is suitable to replace the current ICE propulsion system to minimize the emission problem. Researches prove that fuel cells can have theoretical efficiencies up to 90 percent. Furthermore, since the fuel source used is hydrogen, the energy conversion process is essentially pollution free, as fuel cells can convert hydrogen and the oxygen in the air directly to electricity with water vapour as the by-product [3]. For every EV the electric propulsion system consists of three main elements which is power electronic converter, motor, and motor controller [1].

The study is concurrently produced with the development of an urban concept car electrical motor propulsion system performances designed by the UiTM Eco-Planet team for the

Shell Eco Marathon Asia competition. It is a fully electric

Manuscript received May 14, 2015; revised October 5, 2015. This work was supported in part by the Research Management Institute (RMI), Universiti Teknologi MARA (UiTM) under the MOE FRGS grant (600-RMI/FRGS 5/3 (54/2012). Paper title: DC Brushed Electrical Motor Performance Analysis Study of a Proton Exchange Membrane Fuel Cell (PEMFC) Automotive Propulsion System.

The authors are with the Department of Mechanical, Faculty of Mechanical Engineering, Universiti Teknologi MARA (UiTM), Shah Alam, 40450 Selangor Darul Ehsan, Malaysia (e-mail: firdaus.othman@ymail.com, fettarmes@hotmail.com, syamjenal@yahoo.com; imransainan@yahoo.com). propulsion system which used $1 \mathrm{~kW}$ open cathode Horizon H-1000 Proton Exchange Membrane Fuel Cell (PEMFC) as the main power supply. The DC brushed and brushless motor are used and the performances are compared based on the Shell Eco Marathon competition rules and regulations. The studied propulsion system was placed on the customs-built test bench which imitates the urban concept car performances and on track load conditions.

The study was done with an aim to produce fuel cell electrical propulsion system data mapping and to analyse the efficiency of DC brushed electrical motor for an urban car. The experimental variable such as loads and gear ratios are manipulated to give effect on the motor performances. By affecting the electrical input power, it will directly give reflection on the motor performances which is represented by the mechanical output power.

\section{THEORETICAL BACKGROUND}

\section{A. Electrical DC Motor}

Electrical motor generates maximum torque at zero speed. It has a constant torque because it used a magnetic field. In the small motor size, the low speed high torque is reduced, either by the electronic controller, or by the internal resistance of the battery supplying the motor to avoid motor damage as a result from extremely high value of current [4]. There are several types of electrical motor such as induction motor, brushed motor, brushless motor and switched reluctance motor [5]. DC brushed motor is the simplest form of electrical motor. DC brushed motor is very widely used in applications such as portable tools, toys, electrically operated windows in cars, and small domestic appliances such as hair dryers, and even if they are AC mains powered [6]. The whole arrangement consists of a set of brush-holders mounted close to the commutator [7].

\section{B. Electrical Motor Performance}

An electric motor performances are measured in energy terms which the product of voltage and current for the input, and torque and angular speed at the output [6], [7]. DC motors become more efficient as their size increases and also affected by the speed of a motor [6]. The efficiency of DC motor can also be improved by consideration of motor temperature with proper cooling method [6]. At lower a temperature resistance of the windings is reduces. Speed range of the motor required is generally determined by the type of application. The higher operating speed can be accounted for the components of trapezoidal speed curve 
which resulting in an average speed equal to the movement speed [6], [8].

\section{EXPERIMENTAL METHOD}

The study starts with the identification of the problem based on the UiTM Eco Planet Urban Concept car performance in Shell Eco-Marathon Asia 2012/2013. The problems lead to the objective for this project which is to identify the optimum electric motor configuration. The thought process for the study began with the research on the related literatures that provided background knowledge regarding the study. The research focuses on the fundamentals and applications based on the electrical motor performance analysis study of Proton Exchange Membrane Fuel Cell (PEMFC) automotive electrical propulsion system. The research covered about the electrical vehicle, electrical propulsion system, type of DC motor and DC motor characteristics.

The electrical propulsion system design consists of two main components. The first component is fuel cell electric supply system and the second component is the motor propulsion system. The fuel cell electric supply system is consisted of hydrogen tank, PEMFC stack, auxiliary battery, and fuel cell system. The motor propulsion system is consisted of electric motor speed controller (ESC), electric motor, mechanical transmission and wheel.

For the study, the performance of DC brushed motor was selected to be compared for different parameter and the characteristics for the motor are shown in the following Table I.

TABLE I: THE DC MIDWEST BRUSHED MOTOR SPECIFICATION

\begin{tabular}{ll}
\hline Parameter & Description \\
\hline Manufactured by & MIDWEST MOTION \\
Model & PRODUCT \\
Voltage Constant & $59 \mathrm{rpm} / \mathrm{V}$ \\
Torque Constant & $0.1624 \mathrm{~N} . \mathrm{m} / \mathrm{A}$ \\
Rated Voltage & $36 \mathrm{~V}$ \\
No load current & $0.80 \mathrm{~A}$ \\
Rated Speed & $1864 \mathrm{rpm}$ \\
Rated Output Power & $579 \mathrm{~W}$ \\
\hline
\end{tabular}

To obtain the optimum configuration of motor performances, both motor are experimented in several conditions shows in Table II below:

\begin{tabular}{ll}
\multicolumn{2}{c}{ TABLE II: FIXED VARIABLES } \\
\hline \multicolumn{1}{c}{ Variables } & Details \\
\hline $\begin{array}{l}\text { Continuous Variable } \\
\text { Transmissions (CVT) gear ratio } \\
\text { position }\end{array}$ & $60 ; 160 ; 260 ; 360 ; 460 ; 560$ \\
Load (A) & $10 ; 15 ; 20 ; 25 ; 30$ \\
Total distance (km) & 1.2 \\
Time to complete $(\mathrm{s})$ & $\leq 180$ \\
\hline
\end{tabular}

By applying the fixed variables, the following dependent variables are obtained:

a) Average voltage, current, input and output consumption power

b) Torque

c) Speed
Fig. 1 shows the custom-built test bench located in UiTM Mechanical Engineering Propulsion Lab. All the components involve are identified. The components used are hydrogen fuel cell stack as the voltage source, fuel cell control system, mechanical gears, CVT system and sensors.

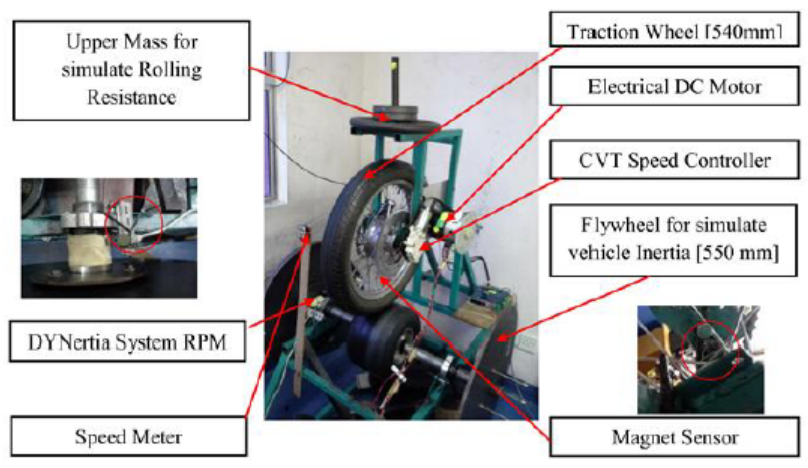

Fig. 1. Custom-built test bench.

\section{DATA ANALYSIS AND DisCUSSION}

For the urban concept vehicle propulsion system, it contains hydrogen gas tank, PEMFC stack, auxiliary battery and fuel cell system. The hydrogen gas is supplied directly to the PEMFC with 0.5 to 0.65 bar pressure. The system used the open cathode $1 \mathrm{~kW}$ PEMFC stack. The PEMFC stack is controlled by the fuel cell system. The system contains of fuel cell controller, power relay, DC-DC controller, on-off button, capacitor, voltage and current control regulator, throttle and continuously variable transmission (CVT) controller.

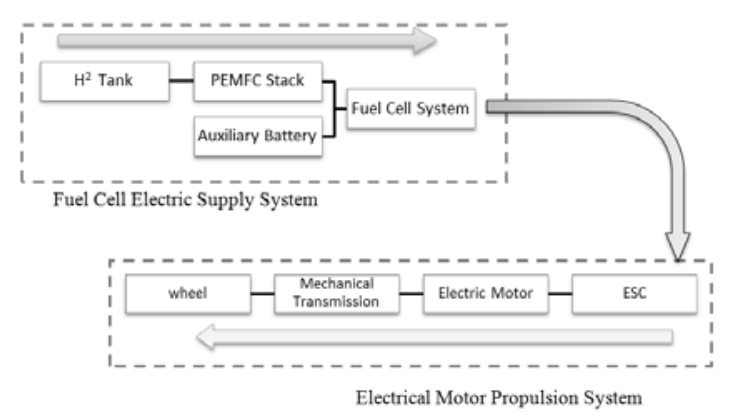

Fig. 2. Fuel cell propulsion system design.

The auxiliary battery contains $12 \mathrm{~V}$ and work to give a start-up to fuel cell controller. The fuel cell controller work to control the system on the PEMFC stack such as the suction fan and the hydrogen flow rate into the stack. The power relay will cut off the supply voltage from the auxiliary battery and replaced by the PEMFC as the main power supply. The capacitor work to store current as a backup for the system during purge activity on PEMFC. The voltage from the fuel cell will be regulated in DC-DC converter before reaching the CVT controller. Fig. 2 illustrated the Fuel Cell Propulsion system design used in urban concept vehicle.

$$
\text { Motor Efficiency, } \eta=\frac{\text { Mechanical Output Power }}{\text { Mechanical Input Power }} \times 100 \%
$$

Equation (1) shows the relationship between electrical input power and mechanical output power that can be demonstrated in term of the motor performance efficiency. 


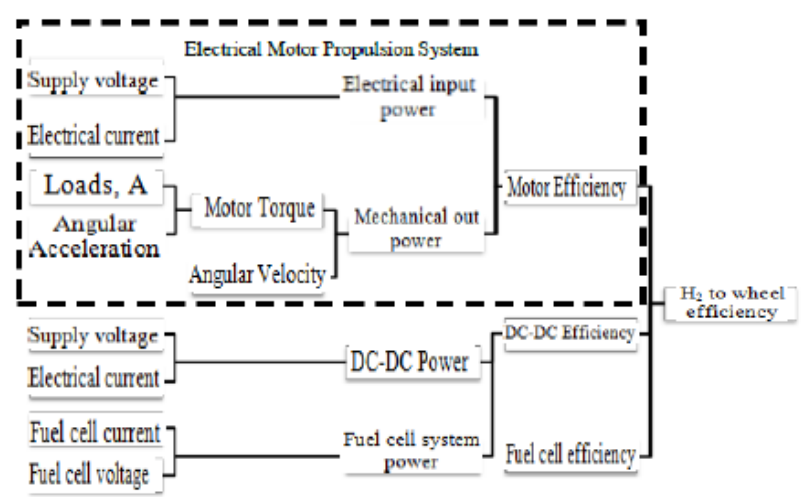

Fig. 3. Hydrogen fuel cell system data mapping.

Although there are other related systems in Hydrogen Fuel Cell system data mapping showed in Fig. 3, the study only focusing on to obtain the motor efficiency for the electrical motor propulsion system.

$$
\text { Electrical Input Power, Pin }=I V
$$

In order to analyse the motor performances, the relationship between each parameter were determined. Using (2), the electrical input power is depends on the supply voltage and the current for turning the motor. The experimental data proved on this behaviour, where the motor current is at constant value as the voltage increase during the acceleration time. As the voltage reaches its maximum value which is $36 \mathrm{~V}$, the motor current value started to drop and this is called the constant speed condition.

Fig. 4 shows the example of the experimental result to give some overview on the relationship between voltage and motor current. This kind of behaviour occurred for all type of DC motor.

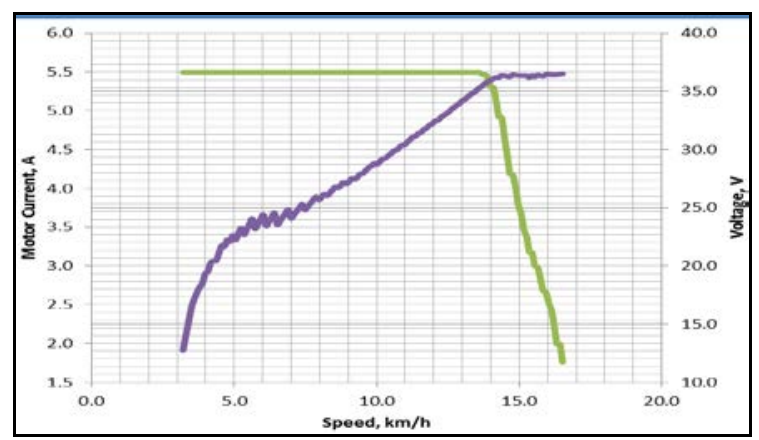

Fig. 4. Behavior of motor current, A with voltage, V.

As for the mechanical output power, the value is determined by the torque and also the angular velocity produced by the motor.

$$
\text { Mechanical Output Power, Pout }=\text { Tw }
$$

Equation (3) represents the relationship for the mechanical output power. The same behaviour as the motor current occurs for the torque value. Different from the internal combustion engine, the torque for the electrical motor is at maximum during acceleration and decrease at the constant speed condition. The amount of torque will reflect the value for the mechanical output power. Fig. 5 shows the example from the experimental data for the torque behaviour.

Equation (4) used to define the torque value on the experiment. The value of I is represent the load in term of electrical current. The value of the load current was set to be varying from 10A up to $30 \mathrm{~A}$ with increment of 5A. By referring to (4) the value of torque will definitely increase as the loads increase. With the effect of loads on torque, and with the higher value of torque, it will affect the performance by shortening the acceleration time. The acceleration time can also be defined as the time for the motor torque to overtake the torque for the vehicle. Therefore the load and motor torque change inversely proportional with the acceleration time. Fig. 6 illustrates the relationship between motor torque and load with respect to the vehicle speed.

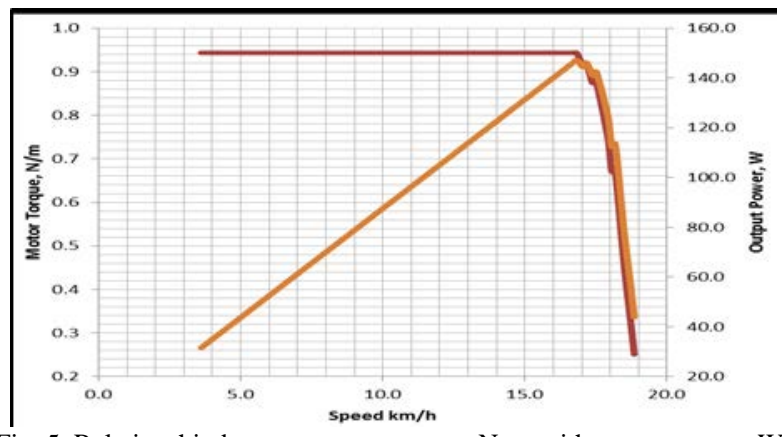

Fig. 5. Relationship between motor torque, N.m. with output power, W.

$$
\text { Mortor Torque, } \tau=I \alpha
$$

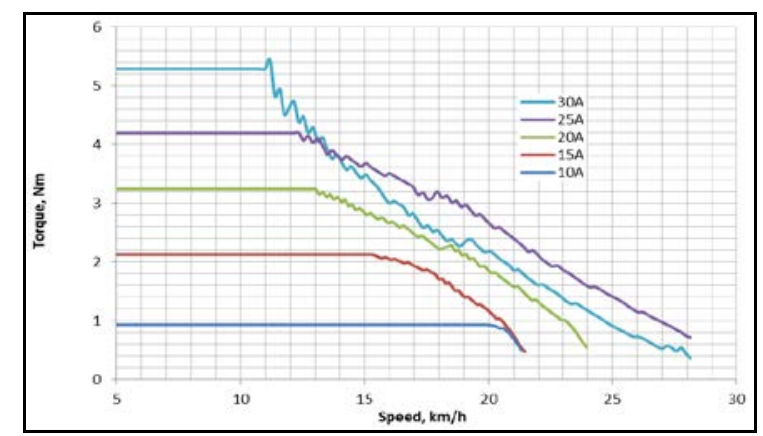

Fig. 6. Graph of torque, N.m. versus speed, km/h for (Position 360; all loads).

As for the speed, it will effected by changing the gear ratio using CVT. Using the NuVinchi CVT for the experiment, there are total 900 positions where each position will represent the applied gear ratio. The position on CVT can be controlled using the CVT controller and it can be set to go under-drive or over-drive condition. In order to limit the speed to go below $28 \mathrm{~km} / \mathrm{h}, 6$ CVT positions are selected. The position varies from 60 to 560 with increment of 100 . As the CVT position increase the gear ratio decrease which make the wheel turns faster than the motor and it is called under drive conditions. Same goes with the speed, the speed change and increase proportionally with the CVT position.

The following Fig. 7 shows the relationship between the effects of CVT position with completion time as the speed increased proportionally.

Fig. 8 represents the summarization on the best CVT position for the motor performances. For the Shell Eco Marathon Asia competition, several areas were focused to be analyzed. The focused areas are more to differentiate the performance of the brushed motor based on the value for motor current, motor voltage, motor torque, input and output power, and the motor efficiency.

All the extracted data being analyzed and compared with each other in order to obtain the best CVT position. The CVT positions must be able to spin the wheel to be able to 
complete the experiment with below 180s and having the lowest input power consumption. The best performance selected based on the lowest use of the input power consumption during operation.

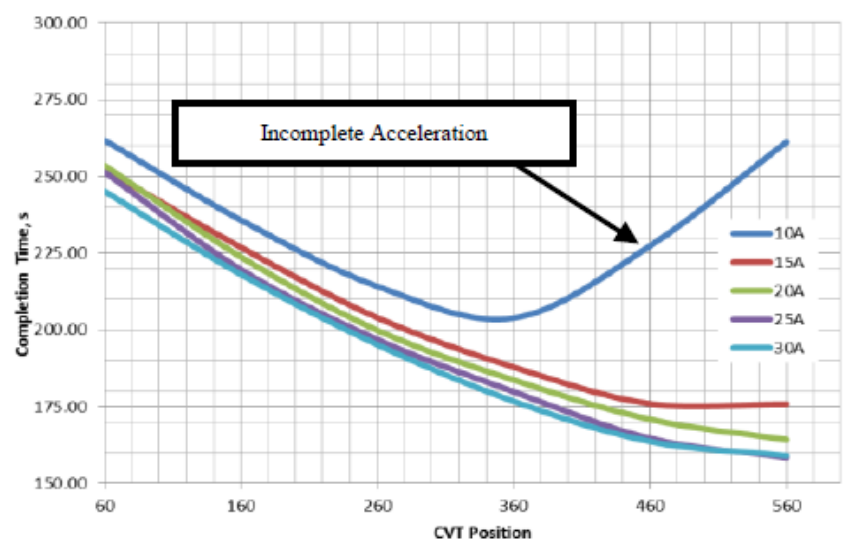

Fig. 7. Graph of completion times versus CVT position (All Positions; all Loads).

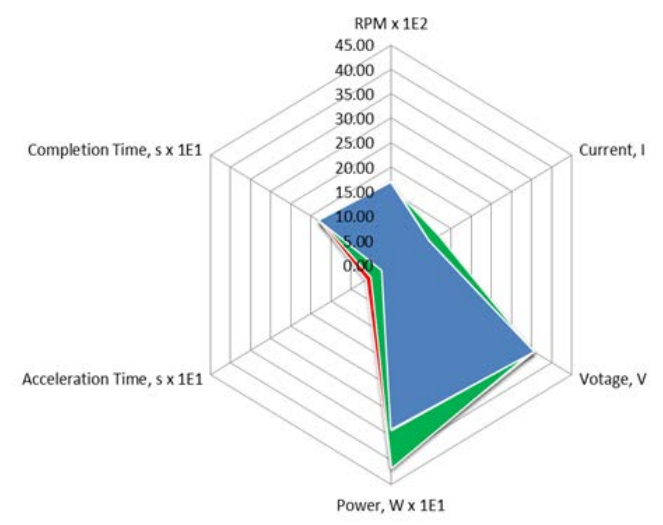

- Position 460, 15A || Position 460, 20A = Position 360, 30A || Position 360, 25

Fig. 8. Summarization chart on midwest best performance.

The chart in Fig. 8 shows the differences in six parameters involved in motor performances. By referring to the data of 30 different conditions, only 4 conditions satisfied the requirement.

Based on the completion time from summarization chart above, the best performance came out from load 25A with CVT position 360 conditions. The best performance selected based on the lowest use of the input power consumption during operation.

\section{CONCLUSION}

From the study, several conclusions can be drawn based on the experimental data:

1) For $1 \mathrm{~kW}$ PEMFC, the best performances of Midwest brushed motor obtain between CVT position 360 and 460 with load range of 15 A to $30 \mathrm{~A}$.

2) The efficiency for the Midwest brushed motor can be obtained in speed range of $1510 \mathrm{rpm}$ to $1690 \mathrm{rpm}$.
3) The motor performance data mapping can be used to observe the performances for other type of DC motor for PEMFC electrical propulsion system.

\section{RECOMMENDATION}

1) The data can be improved by comparing with on track result.

2) The result from the study can be used and compared with the performance of DC Brushless motor.

3) The higher capacity of capacitor and hydrogen ballast tank can be added to give back up voltage and avoid the pressure drop during purging activity in hydrogen fuel cell stack.

\section{ACKNOWLEDGEMENT}

The authors would like to thank the Research Management Institute (RMI), Universiti Teknologi MARA (UiTM) to finance the project under the MOE FRGS grant (600-RMI/FRGS 5/3 (54/2012) for supporting this manuscript is gratefully acknowledge.

\section{REFERENCES}

[1] C. C. Chan and Y. S. Wong, "Electric vehicles charge forward," IEEE Power \& Energy Magazine, vol. 2, no. 6, pp. 24-33, 2004.

[2] R. Krishnan, Switched Reluctance Motor Drives: Modelling, Simulation, Analysis, Design, and Applications, Boca Raton, FL: CRC Press, 2001.

[3] A. Frangi, "Lightweight body designs as enablers for alternative powertrain technologies: Understanding cost and environmental performance tradeoffs,” Propulsion Technologies, pp. 40-44, 2001.

[4] P. Bolognesi, F. V. Conte, B. G. Lo, and M. Pasquali, "Hy-Sim, a modular simulator for hybrid-electric vehicles," in Proc. the 18th International Electric Vehicle Symposium, 2001, EVS18.

[5] M. Zeraoulia, M. E. Benbouzi, and D. Diallo, "Electric motor drive selection issues for HEV propulsion systems: A comparative study," IEEE Transactions on Vehicular Technology, vol. 55, no. 6, pp. 1756-1764, 2006.

[6] J. Larminie and J. Lowry, Electric Vehicle Technology Explained. Hoboken, N. J: Wiley, 2003.

[7] M. Ehsani, Modern Electric, Hybrid Electric, and Fuel Cell Vehicles: Fundamentals, Theory, and Design, Boca Raton: CRC Press, 2005.

[8] P. Yedamale, "Brushless DC (BLDC) motor fundamentals," Microchip Technology Inc., vol. 20, pp. 3-15, 2003.

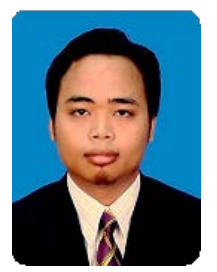

F. Othman was born in Klang, Selangor Malaysia, March 1, 1989. Completed his diploma in mechanical engineering from Universiti Teknologi Mara (UiTM) Permatang Pauh on 2011. He is currently a final year student in Bachelor of Engineering (Hons.) Mechanical Universiti Teknologi Mara (UiTM) Shah Alam.

He participated with UiTM Eco-Planet technical team for Shell Eco-Marathon Asian competition in 2013 competing at the Sepang International Circuit. He completed his practical training with Bahagian Sokongan Teknikal (BST), Agensi Nuklear Malaysia under the Development of Borehole Mechanical Automation project. Currently, he focused study on the Hydrogen Proton Exchange Membrane Feul Cell (PEMFC) electrical propulsion system. 